\title{
Biliary Obstruction Induces Extremely Elevated Serum CA 19-9 Levels: Case Report
}

\author{
Cem Onal $^{\mathrm{a}}$ Tamer Colakoglu $^{\mathrm{b}}$ Serife N. Ulusan ${ }^{c} \quad$ Ali F. Yapar ${ }^{\mathrm{d}}$ Fazilet Kayaselcuk $^{\mathrm{e}}$
}

${ }^{a}$ Department of Radiation Oncology, Baskent University Faculty of Medicine, Adana,

${ }^{b}$ Department of General Surgery, 'Department of Radiology, 'Department of Nuclear Medicine,

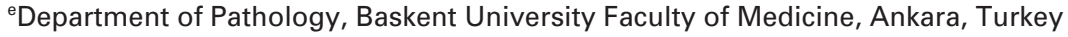

\section{Keywords}

CA 19-9 - Biliary disease - Biliary obstruction .

Tumor marker

\section{Summary}

Background: Assessment of carbohydrate antigen (CA) 19-9 levels is used for diagnosis and follow-up of pancreaticobiliary cancers, and high levels of this biomarker are suggestive of a malignancy. CA 19-9 may also be elevated in patients with conditions other than tumors, such as cholestasis, biliary obstruction, and cholecystitis. Case Report: A 50-year-old male patient presented with jaundice and elevated CA 19-9 levels (161,902 IU/ml). Repeated biopsies of the common bile duct revealed no malignancies. Radiological findings indicated a mass protruding through the common bile duct. Positron emission tomography demonstrated increased ${ }^{18} \mathrm{~F}$-fluoro2-deoxy-D-glucose uptake in the liver and a mass resembling metastasis was detected. A Whipple procedure was performed and demonstrated no tumor. Postoperatively, CA 19-9 levels decreased to within normal limits (27 IU/ml). Conclusion: These results indicate that CA 19-9 levels should not be the sole criterion for a diagnosis of malignancy. Although other analytical tools may aid diagnosis, surgical exploration may be required in some instances to avoid misdiagnosis and determine whether radiological results are falsely positive.

\section{Introduction}

Carbohydrate antigen (CA) 19-9 was originally identified by a murine monoclonal antibody that specifically bound human colorectal carcinoma cells, and has been used for preoperative

\section{Schlüsselwörter}

CA 19-9 · Gallenerkrankung · Biliäre Obstruktion · Tumormarker

\section{Zusammenfassung}

Hintergrund: Die Bestimmung von Carbohydrate-Antigen (CA)-19-9-Spiegeln wird zur Diagnose und bei der Nachsorge von pankreatobiliären Karzinomen verwendet und hohe Spiegel dieses Biomarkers weisen auf eine maligne Erkrankung hin. Der CA-19-9-Spiegel kann auch bei Patienten mit nichtmalignen Erkrankungen erhöht sein, z.B. Cholostase, biliäre Obstruktio und Cholecystitis. Fallbericht: Ein 50-jähriger Patient wurde mit Ikterus und einem erhöhten CA-19-9-Spiegel (161902 IU/ml) vorstellig. Wiederholte Biopsien des Gallenganges ergaben keine Malignität. Der radiologische Befund ergab eine Läsion, die in den Gallengang ragte. Die Positronenemissionstomography zeigte eine erhöhte ${ }^{18} \mathrm{~F}$-Fluoro-2-Deoxy-D-Glucose-Aufnahme in der Leber und eine Läsion, die einer Metastase ähnelte. Eine Whipple-Operation wurde durchgeführt und es wurde kein Tumor gefunden. Der postoperative CA-19-9-Spiegel sank auf normale Werte $(27 \mathrm{IU} / \mathrm{ml})$. Schlussfolgerung: Dieses Ergebnis zeigt, dass der CA-19-9-Spiegel nicht das einzige Kriterium für die Diagnose einer malignen Erkrankung sein sollte. Obwohl andere Analyseinstrumente die Diagnose unterstützen können, ist in manchen Fällen die operative Exploration notwendig, um Missdiagnosen zu vermeiden und festzustellen, ob die radiologischen Befunde falsch positiv waren.

staging, resectability assessment, and prognosis of pancreatobiliary cancer, as well as diagnosis of tumor recurrence during follow-up [1]. However, the diagnostic accuracy of CA 19-9 is likely lower than previously thought because CA 19-9 is elevated in some cases, such as cholecystitis, pancreatitis, and

\section{KARGER \\ Fax +497614520714 \\ Information@Karger.de}

www.karger.com (c) 2012 S. Karger GmbH, Freiburg

0378-584X/12/3512-0780\$38.00/0

Accessible online at:

www.karger.com/onk
Cem Onal, MD

Department of Radiation Oncology

Adana Research and Treatment Centre, Baskent University Faculty of Medicine

Adana 01120, Turkey

hcemonal@hotmail.com 
choledocholithiasis [2, 3]. Despite these data, many clinicians still strongly associate elevated CA 19-9 levels with cancer [3]. Here, we report an interesting case of extremely elevated CA 19-9 levels in which the clinical, radiological, and laboratory findings all indicated pancreaticobiliary carcinoma, but biopsies proved the condition was benign.

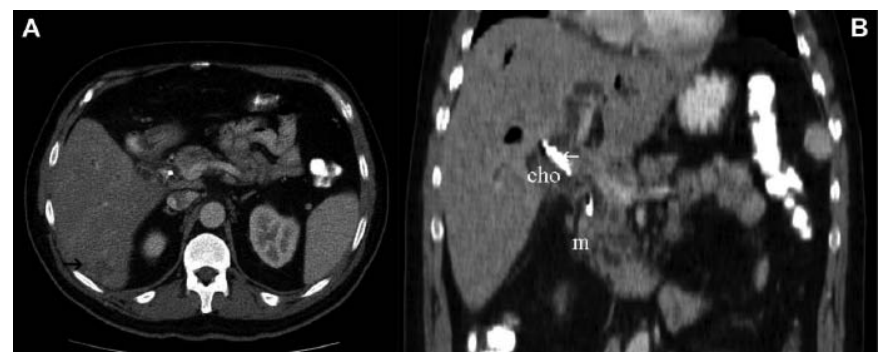

Fig. 1. Intravenous and oral contrast-enhanced computed tomography (CT) images of the liver and common bile duct. A Axial images show irregular subcapsular liver mass $\left(3 \times 4 \times 5 \mathrm{~cm}^{3}\right)$ in segment 6 of the liver (black arrow) and coronal multiplanar reconstruction (minimum intensity projection). B Axial images reveal a mass (m) protruding into the dilated common bile duct (cho) lumen. White arrow: biliary stent.
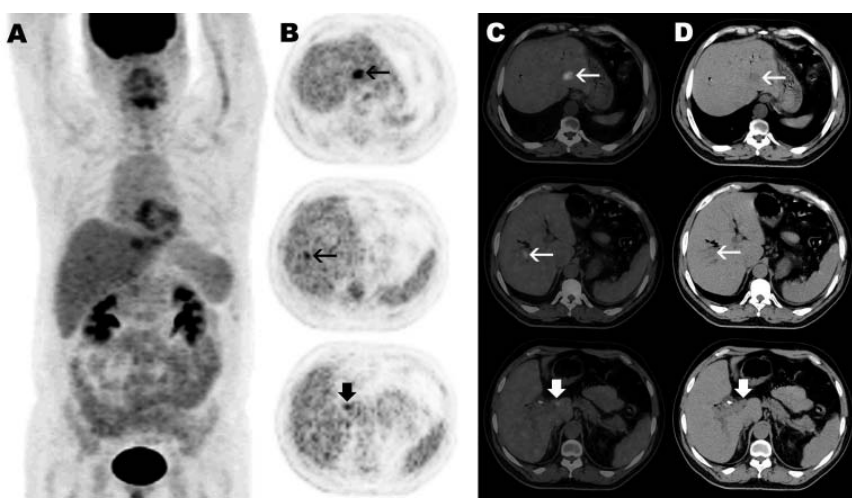

Fig. 2. Positron emission tomography (PET) images taken after biliary catheter insertion. A Maximum intensity projection; B transaxial PET images; C merged CT and PET images; and D CT images. Images show hypermetabolic hypodense lesions indicative of metastasis on segments 2 and 7 (SUVmax $=5.8$ ) (thin rows), as well as a hypodense lesion with increased $\left[{ }^{18} \mathrm{~F}\right]$ fluoro-2-deoxy-D-glucose $(\mathrm{FDG})$ uptake (SUVmax $=4.4$ ) located anterior to the caudate lobe (bold row).

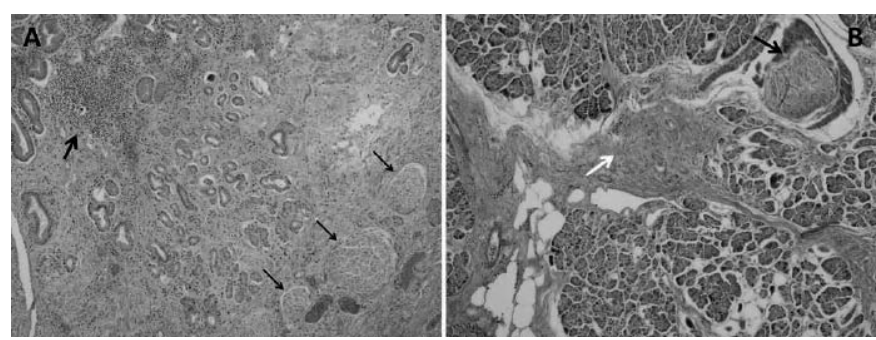

Fig. 3. A Histopathological appearance of the periampullary region (hematoxylin and eosin $(\mathrm{H} \& \mathrm{E}), \times 200)$ demonstrating chronic inflammation (bold arrow). The nerves appear hypertrophic (thin arrows) due chronic irritation of gallstones in the common bile duct. B Histopathological appearance of the pancreatic tissue $(\mathrm{H} \& \mathrm{E}, \times 200)$ indicative of chronic pancreatitis. Multiple nerve bundles are evident and Langerhans islands were scattered. Additionally, a fibrotic region (white arrow) and hypertrophic sinus are visible.

\section{Case Report}

A 50-year-old male, who had been experiencing painless jaundice for 15 days, was admitted to our hospital with jaundice and scleral icterus. Past medical history revealed that, due to cholecystitis, he had undergone a laparoscopic cholecystectomy 10 years previously. Laboratory test results showed markedly elevated transaminase, alkaline phosphatase, $\gamma$-glutamyl transpeptidase (GGT), and total bilirubin levels. CA 19-9 levels were exceedingly high at 161,902 IU/ml (normal range between 0 and $36 \mathrm{IU} / \mathrm{ml})$. An internal stent was placed and biopsy was taken, which revealed chronic inflammation and regenerative changes. On abdominal computed tomography (CT), a 2-cm mass protruding into the lumen and a $3 \times 4 \times 5 \mathrm{~cm}^{3}$ irregular mass resembling metastasis was located in segment 6 of the liver (fig. 1A, B). Positron emission tomography (PET)/CT scan was performed, which revealed hypermetabolic hypodense lesions resembling metastasis on liver segments 2 and 7 (standardized uptake value [SUV] $\max =5.8)$. A $14 \times 11 \mathrm{~mm}^{2}$ hypodense lesion with increased $\left[{ }^{18} \mathrm{~F}\right]$ fluoro-2-deoxy-D-glucose (FDG) uptake (SUVmax $=4.4$ ) located anterior to the caudate lobe was also visible (fig. 2). An endoscopic biopsy demonstrated chronic inflammation and regenerative changes. Because the radiological and PET/CT findings indicated a tumor at the common bile duct with liver metastasis, our Oncology Board adjudicated that surgical exploration should be undertaken. On surgical exploration, the common bile duct was found to have grown to $4 \mathrm{~cm}$ in diameter and an inferior-located fibrotic mass was observed. An exophytic mass on liver segment 7 resembling hemangioma was also evident. A Whipple procedure and end-to-end pancreaticojejunostomy, choledocojejunostomy, and gastrojejunostomy were performed. No complications occurred during or after surgery. The pathological findings were chronic active inflammation with 23 non-metastatic lymph nodes (fig. 3A and B). Postoperative bilirubin and transaminase levels were within normal limits, and CA 19-9 levels decreased to $25 \mathrm{IU} / \mathrm{ml}$.

\section{Discussion}

The glycoprotein CA 19-9 was initially described as a biomarker for colorectal cancer, and its association with pancreatic cancer was reported later. However, non-tumoral conditions may also increase CA 19-9 levels; therefore, elevated levels of this marker should be managed cautiously. This is the first case in which both elevated CA 19-9 and radiological findings (CT and PET/CT) strongly supported the evidence of malignancy, but the surgical pathological findings indicated that a malignancy was not the cause of the extremely elevated CA 19-9 levels.

Frequent false-positive results negatively impact the clinical use of CA 19-9. To improve the clinical use of this biomarker, various methods have been investigated to improve sensitivity and specificity. In pancreatic cancer, CA 19-9 has been reported to have $70-80 \%$ sensitivity and $80-90 \%$ specificity in tumor diagnosis [4]. Marrelli et al. [3] reported that elevated CA 19-9 levels (> $37 \mathrm{U} / \mathrm{ml})$ were found in $61 \%$ of benign cases and $86 \%$ of malignancies. In several studies, cholestasis and obstructive jaundice were also associated with the highest CA 19-9 false-positive rates. Katsanos et al. [5] and Milinois et al. [6] reported 100-fold increases in postcholectomy CA 19-9 levels. Basso et al. [7] reported results higher than $10,000 \mathrm{IU} / \mathrm{ml}$ in 4 out of 30 patients with benign 
stenosis of the main bile duct, including 1 patient with levels higher than 100,000 KU/1. In another report, Dorizzi et al. [8] reported the highest levels of CA 19-9 thus far, 405,000 IU/ml, as a result of a benign condition. An explanation for these extraordinarily high levels is that the biliary epithelial cells produced large amounts of CA 19-9, which accumulated due to reduced hepatobiliary clearance of CA 19-9 as a result of cholestasis. CA 19-9 levels may reach very high levels in benign conditions, especially in obstructive diseases. Our findings are in line with a previous study on 164 patients with elevated CA 19-9 levels, which showed a positive correlation between elevated bilirubin and CA 19-9-levels [9]. In addition, an improvement of jaundice was associated with a decline in CA 19-9 levels. Therefore, in patients with biliary lesions and a suspected malignancy, serum CA 19-9 levels should be measured before and after relief of the obstruction.

Giving undue credence to elevated CA 19-9 levels could lead to a misdiagnosis of a pancreatic or biliary malignancy, despite a lack of radiological, surgical, and endoscopic results supporting this diagnosis. Therefore, radiological findings and, in some cases, surgical interventions should be used in addition to CA 19-9 assessment for an accurate diagnosis. Although extremely high CA 19-9 levels, together with clinical and radiological findings may implicate a malignancy, this is not always true, as we have shown in our case. PET with $\left[{ }^{18} \mathrm{~F}\right]$ FDG has been successfully used for diagnostic evaluation of cholangiocarcinomas, and is associated with a sensitivity of $92 \%$ and a specificity of $93 \%$ [10]. However, inflammatory processes may cause increased FDG uptake in certain cases, causing false-positive results. Thus, FDG-PET imaging must be interpreted carefully, especially in patients with sclerosing cholangitis, biliary stents, or other benign inflammatory conditions such as cholecystitis [11, 12]. Anderson et al. [11] reported that in 1 of 7 patients with sclerosing cholangitis in their series, FDG-PET imaging was falsely interpreted as indicating malignant disease. Kluge et al. [13] reported a similar false-positive rate. The type of preoperative assessment methods make the present case, in which we investigated beyond CA 19-9 level assessment, distinct from those reported by others. We performed PET/CT to rule out malignancy, as well as systemic metastasis if there was a tumor. The increased FDG uptake that occurred in this case is likely the result of recurrent biopsies taken from the common bile duct and a long period of biliary obstruction that caused inflammation, both of which led to false-positive results.

\section{Conclusion}

Although the CA 19-9 biomarker is indicative of malignancy, it cannot be used alone to diagnose cancer. The sine qua non includes medical history, clinical examination, appropriate radiological methods, and follow-up. However, it should be noted that radiological methods and PET/CT might lead to false-positive results. A multidisciplinary approach, sometimes including surgical interventions, is required for both accurate diagnoses and making correct decisions about treatment modalities.

\section{Disclosure Statement}

We have no personal or financial conflict of interest and have not entered into any agreement that could interfere with our access to the data on the research, or upon our ability to analyze the data independently, to prepare manuscripts, and to publish them.

\section{References}

${ }_{1}$ Boeck S, Schulz C, Stieber P, et al.: Assessing prognosis in metastatic pancreatic cancer by the serum tumor marker CA 19-9: Pretreatment levels or kinetics during chemotherapy? Onkologie 2007; 30:39-42.

2 Vormittag L, Gleiss A, Scheithauer W, et al.: Limited value of CA 19-9 in predicting early treatment failure in patients with advanced pancreatic cancer. Oncology 2009;77:140-146.

3 Marrelli D, Caruso S, Pedrazzani C, et al.: CA19-9 serum levels in obstructive jaundice: Clinical value in benign and malignant conditions. Am J Surg 2009;198:333-339.

$\checkmark 4$ Goonetilleke KS, Siriwardena AK: Systematic review of carbohydrate antigen (CA 19-9) as a biochemical marker in the diagnosis of pancreatic cancer. Eur J Surg Oncol 2007;33:266-270.
5 Katsanos KH, Kitsanou M, Christodoulou DK, Tsianos EV: High CA 19-9 levels in benign biliary tract diseases. Report of four cases and review of the literature. Eur J Intern Med 2002;13:132-135.

6 Milionis HJ, Elisaf MS, Tsianos EV: Post-cholecystectomy transient hundred-fold increase in CA 19-9. Eur J Gastroenterol Hepatol 1997;9:10131014.

7 Basso D, Fabris C, Plebani M, et al.: Alterations in bilirubin metabolism during extra- and intrahepatic cholestasis. Clin Investig 1992;70:49-54.

8 Dorizzi RM, Di Leo A, Guglielmi A, de Manzoni G: Measurement of serum CA 19-9 in biliary diseases requires great caution. Acta Oncol 2001;40:877878.

9 Mann DV, Edwards R, Ho S, et al: Elevated tumour marker CA19-9: Clinical interpretation and influence of obstructive jaundice. Eur J Surg Oncol 2000;26:474-479.
10 Okamoto K, Koyama I, Miyazawa M, et al.: Preoperative $\left[{ }^{18} \mathrm{~F}\right]$ fluorodeoxyglucose positron emission tomography/computed tomography predicts early recurrence after pancreatic cancer resection. Int J Clin Oncol 2011;16:39-44.

11 Anderson CD, Rice $\mathrm{MH}$, Pinson $\mathrm{CW}$, et al. Fluorodeoxyglucose PET imaging in the evaluation of gallbladder carcinoma and cholangiocarcinoma. J Gastrointest Surg 2004;8:90-97.

12 Wakabayashi H, Akamoto S, Yachida S, et al.: Significance of fluorodeoxyglucose PET imaging in the diagnosis of malignancies in patients with biliary stricture. Eur J Surg Oncol 2005;31:11751179 .

13 Kluge R, Schmidt F, Caca K, et al.: Positron emission tomography with [(18)F]fluoro-2-deoxy-Dglucose for diagnosis and staging of bile duct cancer. Hepatology 2001;33:1029-1035. 